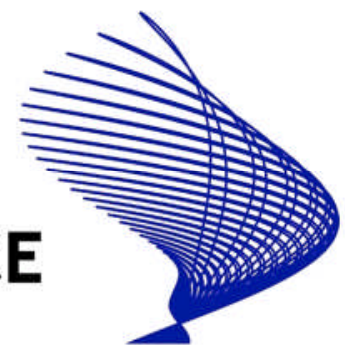

NORFACE MIGRATION Discussion Paper No. 2013-24

\title{
Spillover Effects Of Studying With Immigrant Students; A Quantile Regression Approach
}

Asako Ohinata and Jan C. van Ours 


\title{
Spillover effects of studying with immigrant students; a quantile regression approach
}

\author{
Asako Ohinata* and Jan C. van Ours ${ }^{\dagger}$
}

Version November 5, 2013

\begin{abstract}
We analyze how the share of immigrant children in the classroom affects the educational attainment of native Dutch children in terms of their language and math performance at the end of primary school. Our paper studies the spill-over effects at different parts of the test score distribution of native Dutch students using a quantile regression approach. We find no evidence of negative spillover effects of the classroom presence of immigrant children at the median of the test score distribution. In addition, there is no indication that these spill-over effects are present at other parts of the distribution.
\end{abstract}

JEL classification: I21, J15

Keywords: Immigrant children; Peer effects; Educational attainment

*Department of Economics, University of Leicester, UK; ao160@le.ac.uk

${ }^{\dagger}$ Department of Economics, CentER, Tilburg University, The Netherlands; Department of Economics, University of Melbourne, Parkville, Australia; CESifo, CEPR and IZA; vanours@uvt.nl

The authors would like to thank the seminar and conference participants in European Association of Labour Economics in Turin, Tilburg University, 3rd TEMPO conference in Nuremberg, Royal Economic Society conference in London. The authors gratefully acknowledge financial support from the NORFACE research program on Migration in Europe-Social, Economic, Cultural and Policy Dynamics. 


\section{Introduction}

The increasing presence of immigrant students in European schools has raised concerns among policy makers and public about its potential effects on native students' educational attainment. Immigrant students in Europe often come from lower socioeconomic background and have to adapt to the native language. As a result, they are more likely to require additional teaching resources, leaving fewer resources for the native children. If this is the case, a higher share of immigrant students in the classroom may have a negative effect on the educational attainment of native children. The present paper investigates these spillover effects from immigrant students to native Dutch students in the 8th grade of primary schools.

Evidence from the Netherlands presents an interesting case study for the rest of Europe. As we will discuss in more detail later on, immigrant students in the Netherlands generally come from families with lower education and they often lag behind their native peers. This phenomenon is commonly observed in most European countries and as a result, this paper presents relevant findings to a wider European audience.

Educational spill-over effects from immigrant children to native children have been studied in the United States by Hoxby (1998) and Borjas (2004), who present evidence of immigrant crowding out effects for native students in graduate and postgraduate schools. Other US studies focus on peer effects caused by interactions with immigrant students in the neighborhood and their impact on academic performance of native students (Betts (1998); Betts and Lofstrom (2000); Hunt (2012)).

Evidence from outside the US include Gould et al. (2009), who use the large influx of Jewish immigrants from the former Soviet Union to investigate peer effects on the native Israeli students. Brunello and Rocco (2011) present cross country evidence from 27 European and Anglo-Saxon countries using the 2000, 2003, 2006 and 2009 Program for International Student Assessment (PISA). PISA assesses the cognitive abilities (reading, mathematics, and science) of the 15 year old students in OECD member countries. Jensen and Rasmussen (2011) study immigrant peer effects in Denmark using the 2000 and 2005 PISA and Danish administrative register data. Geay et al. (2013) use data from the British National Pupil Database between 2003 and 2009 to relate the percentage of nonEnglish speaking children aged 12 in England to the educational performance of native children on reading, writing, math within the same school.

Educational spillover effects of immigrant children have also been investigated in the Netherlands. Van der Silk et al. (2006) study the effect of ethnic composition on language 
proficiency of children in grade 4 to 6 . They find that pupils in school classes with a high share of ethnic minorities perform worse but this effect disappears once parental characteristics are taken into account. Maestri (2011) studies the effect of ethnic diversity in a class room finding that this has a positive effect on test scores of minority students. Both of these papers use the same data as we do in the current paper.

In a previous paper, we analyze how the share of immigrant children in the classroom affects the educational attainment of native Dutch children (Ohinata and van Ours (2013)). In this previous study, we use repeated cross sectional data from PIRLS (Progress in International Reading Literacy Study) and TIMSS (Trends in International Mathematics and Science Study) and exploit variation in the share of immigrant students across 4th grade classes within the same school. We conclude that at the conditional mean, there is no strong evidence of negative spillover effects from immigrant children to native Dutch children on reading, maths and science skills.

All of these previous studies including ours examine spill-over effects of immigrant students at the conditional mean of the native students' test score distribution. However, the spill-over effects of immigrant students may be heterogeneous along the test score distribution. For example, a larger share of immigrant students in the classroom may induce teachers to focus more on weaker students if the immigrant students are also performing poorly. This would result in shifting of teaching resources from better students to struggling students. We would then observe an improvement in academic performance among students who previously faced difficulties. The flip-side of this is that academically advantaged native students may struggle more. Providing an answer to such a question requires spill-over effects to be evaluated at different parts of the test score distribution. This is what we aim to do. We extend the existing analysis by employing a Quantile regression approach studying differential spill-over effects of immigrant students on different parts of the test score distribution of native Dutch students.

One major obstacle researchers face when studying the present topic is that immigrant students are not randomly allocated to schools. In fact, immigrant students may enroll in schools with more academically disadvantaged native students. If such non-random allocations are not accounted for, estimated spillover effects are biased. We control for this non-random allocation by exploiting the variation in the number of immigrant students across several 8th grade cohorts from the same school over the years. The identification assumption, therefore, requires that once year and school fixed characteristics are controlled for, students are randomly allocated to the 8th grade across cohorts within 
the same school. This assumption may not hold in reality if, for example, parents avoid schools that enrolled many immigrant students in the previous cohorts. However, in such a case, our estimates would be negatively biased and as a result, our estimates present a lower bound of the potential spillover effects.

Quantiles are not linear operators. This implies that a simple de-meaning approach to take account of unobserved school fixed effects which is often employed in a linear setting cannot be applied. Instead, we employ an estimator proposed by Canay (2011). Canay (2011)'s approach treats the unobserved school characteristics as a simple location shift that does not depend on each quantile. This in turn, implies that the school fixed effects can first be estimated at the conditional mean and the predicted fixed effect values can then be deducted from the dependent variable before estimating the spill-over effects.

In our analysis, we use the rich Dutch longitudinal PRIMA data in which information from students at primary schools in the Netherlands was collected in the period 1996 to 2005. The PRIMA data have several nice features. The data include the Dutch national CITO test scores which provide an overall assessment of educational performance at the end of primary school i.e. for 11-12 year old students in the 8th grade students. In the Netherlands, the outcome of the CITO test is the main determinant for the allocation of students who finished primary school to one of the secondary educational tracks, i.e. preparatory intermediate vocational education, senior general secondary education or pre-university education. It is, therefore, an important educational outcome to study. Moreover, since the CITO test is a national test, the educational achievement of students across schools can be compared. We focus on language and math test scores separately. Furthermore, the same set of schools is observed across cohorts. This allows us to control for unobserved school fixed effects and to identify the peer effects of immigrant students. Finally, the data provide rich information on students, teachers as well as schools.

Our contribution to the literature on spillover effects from immigrant students to the educational performance of native students is threefold. First, we present an analysis in which the focus is on spillover effects across the test score distribution. It is possible that there are no spillover effects for the median students while students at the low end (or the top end) of the skill distribution experience negative/positive effects. Second, as a sensitivity analysis, we are able to investigate spillover effects observed in different grades and not just in 8 th grade. This may be important as potential spillover effects may be different across grades. One possible reason why this may be the case is that academically disadvantaged students are more likely to repeat the same grade twice. If this is the case, 
the 8th grade students that we observe in our data may be self-selected students who had little difficulties with their studies. We, therefore, also study the spillover effects among the 4th and 6th grade students. Third, the use of panel data at the level of schools allows us to take into account the potential selectivity arising from parents choosing particular primary schools for their children. We do not have to rely on within-school variation of the share of immigrants in classrooms.

Our current paper is set-up as follows. Section 2 provides information about immigrants in the Netherlands and Dutch primary schools. Section 3 presents the set-up of our analysis. Section 4 describes our data and presents a descriptive analysis. Section 5 discusses preliminary parameter estimates. Section 6 concludes.

\section{Immigrants and Dutch primary schools}

\section{$2.1 \quad$ Immigrants}

For the purpose of our analysis, we define an immigrant child as a child whose at least one parent was born outside of the Netherlands. Over our sample period of 1996-2005, the overall immigrant population in the Netherlands increased from 2.5 to 3.1 million while the share of immigrants in the Dutch population of about 16 million increased from 16 to 19 percent.

The immigrant population is heterogeneous. First, there is heterogeneity in terms of whether or not children were born in the Netherlands. First-generation immigrants are born outside the Netherlands whilst the second-generation immigrants were born in the Netherlands.

Second, there is a distinction in terms of country of origin. A frequently made distinction is between Western and non-Western immigrants. Western immigrants come from countries in Europe (excluding Turkey), North-America, Oceania, Indonesia or Japan. Non-Western immigrants come from countries in Africa, Latin-America and Asia (excluding Indonesia and Japan) or Turkey.

Many of the characteristics of the Western immigrants are similar to the characteristics of the native Dutch population. However, non-Western immigrants often have a lower educational attainment and a weaker labor market position (see for example Cerveny and van Ours (2013)). The country of origin of non-Western immigrants is related to two events in recent Dutch immigration history. First, there was a flow of immigrants from former Dutch colonies, i.e. from Indonesia after it became independent shortly after the 
second World War and from Surinam in the aftermath of its independence in 1975 and more recently from the Antilles (Ersanilli (2007); Lucassen and Penninx (1997)). The second group of immigrants consist of foreign workers who were recruited in the 1960s and 1970s as guest workers as a response to shortages of labor in the Netherlands. Though hired as temporary workers, many immigrant workers decided to stay in the Netherlands. After recruitment stopped in the early 1970s, immigration in particular from Morocco and Turkey continued because of family formation and unification (Van Ours and Veenman (2005), Ersanilli (2007)). Related to this recent history, in 2005 the four main nonWestern immigrants groups were Turkish, Surinamese, Moroccans and Antilleans. ${ }^{1}$

The immigrant population is not evenly distributed across the Netherlands. Many immigrants live in the four largest cities, i.e. Amsterdam, the Hague, Rotterdam, and Utrecht whereas few immigrants live in rural areas. For example, in 2005 whereas the nationwide share of immigrants was 19 percent, it was 42 percent in Amsterdam, 36 percent in Rotterdam, 40 percent in The Hague and 27 percent in Utrecht. The nationwide share of non-Western immigrants was 10 percent, but it was 28 percent in Amsterdam, 27 percent in Rotterdam and 17 percent in The Hague and Utrecht.

\subsection{Primary schools in the Netherlands}

In the Netherlands, parents have the freedom to choose a school they want their child to attend. Primary schools are funded by the government and in our period of analysis, the size of this funding was dependent on the characteristics of the children. Between 1985 and 2006, the Weighted Student Funding (WSF) was in operation to promote equal educational quality among schools and also to assist schools with a larger number of disadvantaged students (Ladd and Fiske (2009)). The WSF scheme calculated a weighting index for each school by taking into account the immigrant status and the parental education of the parents of the children.

The system is made slightly more complex by the fact that money was not directly paid to each school but rather was given to school boards that had the control over the distribution of the allocated funding across the schools. Nonetheless, Ladd and Fiske (2009) provide evidence that extra funding was allocated mainly to schools in the four largest cities, who as indicated before, have the highest shares of immigrants. The implication of

\footnotetext{
${ }^{1}$ In recent years, economic and political crisis have increased immigrant flows from diverse backgrounds such as Iraq, Iran, Afghanistan, and Somalia. However, the numbers of immigrants from these countries are relatively small compared to the main immigrant groups.
} 
such a treatment is that school principals may have allocated additional resources towards classes with larger numbers of immigrant students. If this is the case, and classes with a high share of immigrant children were being taught by more able teachers or if these classes had better teaching resources, the size of the potentially negative peer effects of immigrant students may have been reduced.

\section{Set-up of the analysis}

If students were randomly allocated to schools, then following Buchinsky (1998), Equation 1 below specifies the $\theta$ th conditional quantile of the test score distribution for the ith individual in 8th grade, th cohort and sth school. ${ }^{2}$

$$
\operatorname{Quant}_{\theta}\left(y_{i t s} \mid X_{i t s}\right)=X_{i t s}^{\prime} \beta_{\theta}
$$

where Quant $_{\theta}\left(\epsilon_{\theta i t s} \mid X_{i t s}\right)=0$ and $\beta_{\theta}$ shows a vector of parameters at $\theta$ th quantile. Furthermore, $y_{i t s}$ is the natural logarithm of the national CITO test scores of Dutch students for language and math. $X_{i t s}$ captures the student, classroom, teacher and parent level characteristics. The key variable is the share of immigrant students in a classroom. The coefficient of this variable reveals the existence of and the direction of the spillover effects. $X_{i t s}$ also includes various information on the gender of the student, parental education, cohort specific fixed effects. Furthermore, teacher's teaching experience and gender are included. In order to capture the level of school resources in each cohort, a variable is included which measures the hours of remedial teaching. As the discussion in Section 2.2 highlights, school funding is allocated depending on the share of immigrants and disadvantaged native students in schools. As a result, controlling for the time variant school resources is essential. Information on remedial teaching was provided by school directors and thus applies to the entire school and not to specific grades. This ensures that the remedial teaching variable measures each school's teaching resources but is not directly correlated with the share of immigrant students in 8th grade.

Evidence from Ladd and Fiske (2009) and Ladd et al. (2010) suggests that students are selectively allocated to schools. In order to account for this selection, we introduce school fixed effects $\alpha_{s}$ :

$$
\operatorname{Quant}_{\theta}\left(y_{i t s} \mid X_{i t s}\right)=X_{i t s}^{\prime} \beta_{\theta}+\alpha_{s}
$$

\footnotetext{
${ }^{2}$ Note that each individual is observed only once in our dataset. It is the set of schools that are observed repeatedly across cohorts.
} 
This specification exploits the variation in the number of immigrant students in the 8th grade over the years. The identification assumption requires that once cohort and school fixed characteristics are controlled for, the 8th grade students in a particular year is comparable to those from another year. ${ }^{3}$ Moreover, the number of immigrant students found in a grade in a particular year is random.

However, $\alpha_{s}$ is unobserved and is likely to be correlated with other covariates. When estimating a quantile model, we cannot apply the standard de-meaning approach, which is frequently employed in the linear setting. This is because quantiles are not linear operators. We, therefore, employ the two-step estimator proposed by Canay (2011). This approach treats $\alpha_{s}$ as a simple location shift and, therefore, does not depend on the quantiles. This implies that the school fixed effects affect the test scores of all students within the same school in the same way regardless of where the students are located in the test score distribution.

The estimator proposed by Canay (2011) involves two steps. First, school fixed effects are estimated at the conditional mean. Second, the estimated fixed effects are deducted from the observed test scores and a quantile regression is performed using the demeaned test scores.

More specifically, the Canay (2011) estimator involves the following steps.

- Step 1: Let $\hat{\beta}_{\bar{\theta}}$ be a $\sqrt{n}$ consistent estimator of $\beta_{\bar{\theta}}$ where $\beta_{\bar{\theta}}$ is a vector of parameters at the conditional mean and $n=\sum_{s=1}^{S} \sum_{t=1}^{T_{s}} n_{s t}$. We can estimate $\hat{\beta}_{\bar{\theta}}$ using the standard within estimator. Then, obtain $\sqrt{n_{s}}$ consistent estimator of $\alpha_{s}$ where $n_{s}=\sum_{t=1}^{T_{s}} n_{s t}$.

$$
\hat{\alpha}_{s} \equiv \frac{1}{n_{s}} \sum_{t=1}^{T_{s}} \sum_{i=1}^{n_{s t}}\left[y_{i s t}-X_{i s t}{ }^{\prime} \hat{\beta}_{\bar{\theta}}\right]
$$

- Step 2: Define $\hat{y}_{i s t} \equiv y_{i s t}-\hat{\alpha}_{s}$. Given $\rho_{q}(u)=u[q-I(u<0)]$, where $I($.$) is an$ indicator function. This then allows us to obtain the $\sqrt{n}$ consistent estimator of $\beta_{\theta}$.

$$
\hat{\beta}_{\theta}=\underset{\theta \in \Theta}{\operatorname{argmin}} \frac{1}{n} \sum_{i=1}^{n}\left[\rho_{q}\left(\hat{y}_{i t s}-X_{i t s}^{\prime} \beta_{\theta}\right)\right]
$$

\footnotetext{
${ }^{3}$ In our previous paper, Ohinata and van Ours (2013), we use PIRLS and TIMSS, which are both repeated cross sectional data. As a result of this, we exploit the variation in the share of immigrant students across classes within the same grade. In contrast, our present paper uses the variation across cohorts. Since students may be allocated non-randomly to classes within the same grade, our present identification strategy is likely to be less sensitive to bias arising from student allocations to their learning environment.
} 
The standard errors are bootstrapped with 200 replications and the clustering at the school level is also taken account of. This involves both the school fixed effects $\hat{\alpha}_{s}^{b}$ and the preliminary $\hat{\beta}^{b}{ }_{\theta}$ to be computed for each bootstrapped sample $b=1, \ldots, B$. The bootstrapped variance covariance matrix for $\hat{\beta}_{\theta}$ is given by

$$
\frac{1}{B-1} \sum_{b=1}^{B}\left(\hat{\beta}_{\theta}^{b}-\bar{\beta}_{\theta}^{b}\right)\left(\hat{\beta}_{\theta}^{b}-\bar{\beta}^{b}{ }^{\prime}\right)^{\prime}
$$

where $\bar{\beta}^{b}{ }_{\theta} \equiv \frac{1}{B-1} \sum_{b=1}^{B} \hat{\beta}^{b}{ }_{\theta}$

\section{Data and descriptive analysis}

\subsection{Data}

Our paper employs a rich Dutch dataset, PRIMA, which is a longitudinal dataset commissioned by the Ministry of Education and coordinated by the Institute for Research of Education (DME). The implementation of the research rested with the Institute for Applied Social Sciences (ITS) of the Catholic University Nijmegen and the SCO-Kohnstamm Institute of the University of Amsterdam. PRIMA collects detailed information from approximately 600 primary schools. ${ }^{4}$ Test scores and individual characteristics were collected from students and their parents. Moreover, information at the classroom, teachers school administrators were also made available.

Our data allows us to observe information on the 4th, 6th and 8th grade students and their parents, as well as details of their teachers and schools. There are 6 surveys conducted every two years since the 1994/95 academic year. However, because the set-up of the first wave was different from the others and comparable variables can only be found between 1996-2005, we ignore the first wave and focus on the time period from 1996 to 2005 .

After primary education all children in the Netherlands go on to secondary education where there are various educational tracks, ranging from preparatory intermediate vocational education to preparatory university education. Admission to a specific educational tracks depends partially on the results of a national test held during the final year of primary school. This national test is the Cito test. The questions in the Cito test

\footnotetext{
${ }^{4}$ This is a representative sample of about 420 schools and an additional sample of about 180 schools with pupils from a lower socio-economic background.
} 
deal with language, math and study skills sometimes supplemented with environmental skills. The language test refers to the Dutch language and concerns spelling words and verbs, sentence or text structure, reading comprehension and the meaning of words. The math test deals with numbers, mental arithmetic, percentages, fractions and doing certain arithmetic calculations as well as dealing with measurements, weights, money and time. The study skills test measure how well children use information sources such as dictionaries, encyclopedias and the telephone directory. There are also questions that involve study texts, maps, tables and graphs. The environmental test refers to questions about geography, history, biology and physics.

The PRIMA dataset contains information about various components of the Cito tests and information about the standard score that is used when deciding about admissions to specific educational tracks in secondary education. However, the various components are not available for every year. The data from 1996/97 do not contain study skills whereas the data from 1998/99 excludes information on study skills and environmental skills. Only the language and math parts of the Cito test are examined over all years. Therefore, we decided to focus on the language and skills components. Cito math test contains 60 questions whereas Cito language test had 60 questions in 1996/97 to 2000/01 but 100 questions in 2002/03 and 2004/05. We account for the discontinuity in the number of questions in the language test by using the logarithm of the score as dependent variable and using survey fixed effects. For the purpose of comparison, the logarithm transformation is also applied for the math test scores.

Students in the Netherlands occasionally repeat the same grade if teachers think that this is necessary for the student to acquire better understanding of the curriculum. To assess the effect of the share of immigrants in the classroom, our baseline analysis excludes Dutch students who repeat the same grade. We do this by limiting the age range of the Dutch students to 11 and 12, since these are the students who should be attending the 8th grade had they not repeated any grades. In addition, in our baseline estimates our sample only includes schools which have only one class of eight grade per cohort. This is to avoid the potential problem of non-random allocation of immigrant students between two classes within the same school. ${ }^{5}$ In a sensitivity analysis, we investigate how robust our findings are to changing the age range or to the inclusion of schools with multiple classes per cohort.

\footnotetext{
${ }^{5}$ Approximately $70 \%$ of schools in our sample only has 1 class per grade. Note that in Ohinata and van Ours (2013), our analysis focuses on schools with at least 2 classes of the same grade as we exploit between classroom variation of the share of immigrants within the same school.
} 


\subsection{Descriptive analysis}

Table 1 illustrates the breakdowns of immigrant groups in our 1996-2005 PRIMA dataset by country of origin. The statistics are calculated by using father's country of origin, but the resulting breakdowns are very similar even if we use mother's country of origin. Column (1) of Table 1 includes all immigrant students in our data, i.e. immigrant students with at least one foreign born parent. This column indeed confirms that the major non-western immigrants in the Netherlands come from Surinam, Antilles, Turkey and Morocco. The second and the third columns each show the number of first and second generation immigrants from different countries, respectively. As illustrated by these two columns, the major immigrant groups are the same regardless of if we look at first or second generation immigrants. However, we predominantly observe the secondgeneration immigrant students in our data. As explained earlier, this is because the majority of non-western immigrants entered the Netherlands during the 1940s-1970s. Therefore, the majority of non-western immigrant students aged 11-12 in our data are second generation immigrants.

Table 2 gives an impression of the mean educational performance of various groups of students. Panel a shows the differences between natives and immigrants. Native students on average have a language score of 41.5 while immigrants students have a language score of 37.1 - a difference of 4.4 on a scale from 0 to 60 , i.e. a difference of $7.3 \%$. For math scores, there is also a difference. While native students have an average math score of 42.1 , immigrants have a score of 38.7 - a difference of $5.7 \%$. These differences are statistically significant. ${ }^{6}$

In panel b, the immigrants are divided by immigrant generations. First-generation immigrants do slightly better than second-generation immigrant students for language, but this is not the case for math. Panel c splits up the immigrant children in two groups according to parental education. This reveals even larger differences in language scores across groups. Immigrant children with highly educated parents have an average language test score of 38.5, those with low educated parents have a score of 35.6. A similar story holds for the maths test scores.

We are not only interested in the mean effects of the share of immigrant children but also in potential differential effects across the test score distribution. To investigate whether there might be such differences, Figure 1 compares Kernel Density estimates

\footnotetext{
${ }^{6}$ See for an analysis of the determinants of the educational attainment of immigrant children in the Netherlands Ohinata and van Ours (2012).
} 
of test scores of native Dutch children in classes where immigrant proportion is smaller than $15 \%$ against the classes in which the immigrant proportion is at least $15 \%$ as an eye-balling exercise. The value $15 \%$ is chosen as this is the average share of immigrant students in our sample. The top and the bottom graphs each presents the estimates for the language and maths test scores, respectively. Both graphs suggest that the effect of immigrant students is not uniform across the distribution of test scores. The distribution of language test scores in classrooms with few immigrant students has a higher peak. The distribution of language test scores in classrooms with many immigrant students is to the left of the other distribution. However, there is no parallel shift. The distribution of the math test scores shows a similar pattern.

The left-hand side graphs of Figure 2 illustrate the relationship between the share of immigrants in the classroom and the educational attainment in terms of the language scores (panel a) and the math scores (panel b). There is a negative relationship between the classroom proportion of immigrant and both the language and math scores. However, it is also clear from figure 2 that there is a lot of variation both in terms of average educational scores as well as in the classroom proportion of immigrants.

The relationships shown in the left-hand side graphs of Figure 2 and in the graphs in Figure 1 are informative but they do not take into account that there are time invariant differences between schools related to parents selecting a particular school on the basis of the share of immigrants. If parents of children with better skills are more likely to choose a school with few immigrants then this selectivity could explain the negative relationship in the left-hand side graphs. Therefore, in the right-hand side graphs of Figure 2, we subtract the within-school means across the grades of the education attainment and the share of immigrants. Somewhat surprisingly, the within transformation reveals a marginally positive relationship between the classroom share of immigrants and the educational attainment of native Dutch children.

\section{$5 \quad$ Parameter estimates}

\subsection{Conditional mean parameter estimates}

Before we present our quantile estimates, Table 3 shows the spillover effects at the conditional mean of the test score distribution. The first three rows present estimates for the language spillover effects whilst the latter three rows include estimates for the maths spillover effects. Both sets of estimates for the language and maths test scores exhibit the 
same pattern. When we estimate the effects without controlling for the various covariates or school fixed effects, the estimated peer effects are significantly negative. The size of the estimates become smaller once we control for the various student/teacher/classroom characteristics, although the estimated effects are still significantly negative. However, if we control for the school fixed effects in addition to the covariates, the negative effects disappear and the estimates suggest marginally positive peer effects from the immigrant to native Dutch students.

\subsection{Baseline parameter estimates}

The quantile estimates of the spillover effects are presented in Table 4 . The first three columns, (1) to (3), give the effects on the language scores, columns (4) to (6) are on maths scores. ${ }^{7}$ For each column, F-test of the equality of coefficients are included. ${ }^{8}$ Columns (1) and (4) show the quantile estimates when we ignore the influence of covariates and schools. For language, it appears that there is a significant effect of the share of immigrants. However, the (absolute) magnitude is smaller the higher up the test scores are in the distribution. In fact, for the 90th percentile, the effect is no longer significantly different from zero. From the equality test shown in the bottom line of the table, we strongly reject the hypothesis of equal spillover effects across the language test score distribution. The magnitude of the effects is much smaller for math test, but the test for equality of the coefficients also reveals that effects are heterogeneous across the test score distribution. Columns (2) and (5) show what happens to the main parameter estimates if we include as explanatory variables personal characteristics (such as age, gender, and parental education) and classroom characteristics. The effects of the immigrant shares are now substantially smaller. Moreover, there is no variation in the size of the effects across the distribution of the test scores. Nevertheless, the overall effects are still significantly negative. The sign and the significance of our estimates change further if we also introduce school fixed effects in addition to the other covariates. Inclusion of the school fixed effects leads the estimates to be positive, albeit all the coefficients are insignificantly different from zero. The coefficients from different quantiles are not different from each other. This seems to suggest that once we take selectivity between schools into account, we no longer observe negative spillover effects from the share of immigrant children in

\footnotetext{
${ }^{7}$ Appendix 2 discusses how the language and math scores are affected by personal characteristics and other classroom characteristics.

${ }^{8}$ This is made possible by estimating the full variance-covariance matrix for the estimators at different quantiles.
} 
the classroom to the educational attainment of native Dutch children.

Comparing the estimates in Table 3 and 4 highlight the fact that our conditional mean estimates are fairly similar to the quantile estimates at the median. This suggests that our conditional test score distribution is likely to be quite symmetric. Moreover, this fact also reassures us that the estimated size and the direction of our quantile estimates are unlikely to depend on the choice of the quantile estimator, i.e. the estimator proposed by Canay (2011).

\subsection{Sensitivity analysis}

To investigate the robustness of our main findings, we perform a wide range of sensitivity analysis whereby all regressions include covariates and school fixed effects. Table 5 shows the additional parameter estimates; panel a for language and panel b for maths.

Because second-generation immigrants by definition have been in the Netherlands since they were born, they are less likely to suffer linguistically than first-generation immigrant children. The first column of Table 5 shows the parameter estimates if we ignore the presence of second-generation immigrant children and focus on the share of first-generation immigrant children in the classroom. There is a negative spillover effect for language test scores but this is only significantly different from zero at the median. Nevertheless, the effect is small. The value of -0.17 indicates that an increase in the share of first-generation immigrants with 10\%-points reduces the language score with $1.7 \%$. As indicated by the equality test, we cannot reject the hypothesis that the effects are constant over the language test score distribution. Over the distribution of the math test scores, some of the effects are positive and others are negative but none of the estimated parameters is significantly different from zero.

In the second and third columns, a distinction is made according to parental education. The second column focuses on immigrant children who have parents with a low educational attainment, i.e. primary school education. Our estimated results suggest that language test is negatively affected by the share of immigrant children with loweducation parents but nowhere across the distribution is the effect significantly different from zero. For the math test, we still find positive spillover effects. Column (3) shows the parameter estimates for the share of immigrant children who have parents with higher education, i.e. lower secondary school or more. For this immigrant group, we observe positive effects of the classroom share of immigrant students for both language and maths test scores. Moreover, with one exception, these coefficients are not significantly different 
from zero.

In columns (4) to (6), we return to the classroom share of all immigrant children, but we adjust the sample of native Dutch children. In column (4), the age restriction is abandoned and the sample also includes Dutch children outside the age range of 11 or 12. Despite the fact that this increases the number of students with more than $40 \%$, these estimates are virtually the same as the baseline estimates of Table 4. Column (5) shows the parameter estimates if we include schools with multiple classes per cohort within the same school. This might introduce a selection bias, since immigrant students may not be randomly allocated to classrooms within the same school. If immigrants are more likely to be allocated to a class in which native Dutch children have lower test scores, this would result in a spurious negative relationship between classroom share of immigrants and educational attainment of native Dutch children. Column (5) shows that some parameter estimates who were insignificantly positive in the baseline are now insignificantly negative. This suggest that there might be a small selection effect, but the magnitude is small. These estimates reassure us of the validity of our identification strategy employed in Ohinata and van Ours (2013) where we exploit the variation in the share of immigrant students across classes within a grade. Finally, column (6) also include schools with multiple classrooms per cohort but instead defines the share of immigrants at the level of the grade and not at the classroom level. If immigrant students are not allocated to classrooms randomly, using the immigrant share calculated at the class level would bias our results. However, this alteration hardly affects the parameter estimates either.

Column (5) of Table 5 reveals that the share of immigrant students do not affect the academic performance of Dutch student who repeatedly attend the 8th grade. However, it is also possible that observed 8th grade students are self-selected students who managed to proceed to 8th grade. If this is the case, our estimates would be positively biased as academically struggling students are no longer included in our sample. In order to investigate this issue, we separately estimate our baseline quantile regressions with covariates and school fixed effects for 4th, 6th and 8th graders. Since the Cito test is only conducted in the 8th grade, the test measure is not available in the other 2 grades. Therefore, we use two alternative measures, namely the language and maths sores based on tests conducted specifically for the PRIMA dataset.

The resulting estimates are presented in Table 6 . These estimates highlight two main findings. First, despite using alternative test score measures, we still do not find 
any spillover effects for 8th graders at the median nor at other parts of the test score distribution (columns (3) and (6)). Second, the majority of the estimates suggest that the immigrant peer effects are minuscule regardless of the grade that we investigate. The findings in this table, therefore, present evidence that student selection over time is not the reason why we find no spillover effects for the 8th grade students in our earlier Tables.

\section{Conclusions}

Now that the share of the immigrant population in many European countries is increasing, there is concern that a higher share of immigrants in a classroom has adverse effects on the educational attainment of native children. We show that at least for Dutch children in primary schools, there is no need for such concern.

In our empirical analysis, we relate the share of immigrant children in the classroom to the educational attainment of native Dutch children in the 8th grade. Previous studies on potential spillover effects have studied conditional mean effects. In contrast to the existing literature, we investigate potential spillover effects across the distribution of test scores, since observing the effects only at the conditional mean may mask heterogeneous effects at different parts of the test score distribution. We use a quantile regression approach to investigate potential spill-over effects at different parts of the test score distribution for native Dutch students.

We account for potential selectivity in the choice of parents who might prefer having their child in a school with a low share of immigrant children. If parents who have children with better educational skills are more likely to choose a school with few immigrants then this would create a spurious negative correlation between immigrant share and educational attainment of native Dutch children. Our solution to this potential selection problem is to focus on within school variation in the share of immigrant children across cohorts, assuming that the student allocation to schools are random across cohorts within the same school. We find no evidence of negative spillover effects neither at the mean or at other parts of the distribution of test scores of native Dutch children. This holds for children in various grades.

We acknowledge that our identification strategy may not hold if native Dutch parents avoid schools that enrolled many immigrant students in previous cohorts. However, in such a case, our estimates would be negatively biased. This is because it is likely that parents who take children out of schools with high shares of immigrant students are likely 
to be more concerned about their children's education. As a result, our estimates present a lower bound of the potential spillover effects. Given that overwhelming majority of our estimates present insignificant positive peer effects from immigrant to native Dutch students, our results would rule out the possibility of negative effect of immigrant students on the native Dutch students. 


\section{References}

Betts, J. R. (1998). Educational crowding out: do immigrants affect the educational attainment of American minorities? In D. Hamermesh and F. Bean (Eds.), Help or Hindrance: The Economic Implications of Immigration for African Americans. Russell Sage Foundation.

Betts, J. R. and M. Lofstrom (2000). The educational attainment of immigrants. In G. Borjas (Ed.), Issues in the Economics of Immigration. University Of Chicago Press.

Borjas, G. J. (2004). Do Foreign Students Crowd Out Native Students from Graduate Programs? National Bureau of Economic Research working paper series.

Brunello, G. and L. Rocco (2011). The Effect of Immigration on the School Performance of Natives: Cross Country Evidence Using PISA Test Scores. IZA Discussion Papers.

Buchinsky, M. (1998). Recent advances in quantile regression models: a practical guideline for empirical research. Journal of Human Resources 33, 88-126.

Canay, I. A. (2011). A simple approach to quantile regression for panel data. The Econometrics Journal 14(3), 368-386.

Cerveny, J. and J. C. van Ours (2013). Unemployment of non-western immigrants in the great recession. De Economist 161, forthcoming.

Ersanilli, E. (2007). Focus migration-country profile:the Netherlands. Hamburg Institute of International Economics (HWWI).

Geay, C., S. McNally, and S. Telhaj (2013). Non-native speakers of english in the classroom: What are the effects on pupil performance? The Economic Journal 123(570), F281-F307.

Gould, E. D., V. Lavy, and M. Daniele Paserman (2009). Does immigration affect the long-term educational outcomes of natives? Quasi-experimental evidence. Economic Journal 119, 1243-1269.

Hoxby, C. M. (1998). Do immigrants crowd disadvantaged american natives out of higher education. In Help or Hindrance: The Economic Implications of Immigration for African Americans, pp. 282-321. New York: Russell Sage Foundation.

Hunt, J. (2012, May). The impact of immigration on the educational attainment of natives. Working Paper 18047, National Bureau of Economic Research.

Jensen, P. and A. Rasmussen (2011). The effect of immigrant concentration in schools on native and immigrant children's reading and math skills. Economics of Education Review 30, 1503-1515.

Ladd, H. F. and E. B. Fiske (2009). Weighted student funding for primary schools: An analysis of the dutch experience. Sanford School of Public Policy Working Paper (Duke University), SAN09-02. 
Ladd, H. F., E. B. Fiske, and N. Ruijs (2010). Parental Choice in the Netherlands: Growing Concerns about Segregation. Stanford Working Paper Series SAN10-02.

Lucassen, J. and R. Penninx (1997). Newcomers: Immigrants and their descendants in the Netherlands 1550-1995. Aksant Academic Pub.

Maestri, V. (2011). Can ethnic diversity have a positive effect on school achievement? Munich Personal RePEc Archive.

Ohinata, A. and J. C. van Ours (2012). Young immigrant children and their educational attainment. Economics Letters 116(3), 288-290.

Ohinata, A. and J. C. van Ours (2013). How immigrant children affect the academic achievement of native Dutch children. Economic Journal 123, F308-F331.

Van der Silk, F. W. P., G. W. J. M. Driessen, and K. L. J. De Bot (2006). Ethnic and socioeconomic class composition and language proficiency: a longitudinal multilevel examination in dutch elementary schools. European Sociological Review 22, 293-308.

Van Ours, J. C. and J. Veenman (2005). The Netherlands: Old emigrants-young immigrant country. In K. Zimmermann (Ed.), European migration: what do we know?, pp. 173-196. Oxford University Press. 


\section{Appendix 1 - Definition of variables}

\section{Dependent variables}

Both Cito test scores we use are part of the national CITO test taken by 8th grade students:

1. Cito Language test: The test examines students' ability on Dutch language and includes questions on spelling, text comprehension, vocabulary test, and the interpretation of sentences. For the waves 1996/97, 1998/99 and 2000/01, the Language component of CITO test was composed of 60 questions; for the waves 2002/03 and 2004/05 this was 100 questions. In the descriptive analysis, the language test scores are rescaled for the last two waves by multiplying with 0.6. The differences across the waves are taken into account by taking the logarithms of the scores and including wave fixed effects in the empirical analysis.

2. Cito Mathematics test: The test covers topics on numbers, percentages, fractions, basic algebra, weights, money and time. The Mathematics test consists of 60 questions.

Both PRIMA Language and Maths test scores are administered by the Dutch National Institute for Educational Measurement as part of the PRIMA study and were taken by 4,6, and 8th grade students. The tests come from a system for following pupil achievements in primary education developed by the CITO group. The aim of these tests is to observe to what extent students master various elements of the curriculum. The tests for the same grade levels are identical each year. This ensures that the comparison of achievement levels over time is possible. The scores are also comparable between grades.

\section{Explanatory variables}

1. Share of immigrant students (in proportion); in some of the estimates we focus on a specific immigrant group.

2. Number of hours of remedial teaching as reported by the school directors

3. 1 if the student is male

4. Age of students in the 8th grade

5. 1 if the teacher is male

6. Years of teaching experiences of the 8 th grade teacher

7. Number of students in the 8th grade

8. 1 if students are studying with students from other grades.

9. Dummy variables for PRIMA waves of 1998/99, 2000/01, 2002/03, 2004/05

10. Father's education 

(a) 1 if primary school education (base category)
(b) 1 if lower secondary school education
(c) 1 if upper secondary school education
(d) 1 if University education

11. Mother's education
(a) 1 if primary school education (base category)
(b) 1 if lower secondary school education
(c) 1 if upper secondary school education
(d) 1 if University education

Means and standard deviation of the variables in our analysis are shown below:

\begin{tabular}{lcc}
\hline & \multicolumn{2}{c}{ Dutch students } \\
Variable & Mean & S.D \\
\hline Cito test (Language) & 41.9 & 9.6 \\
Cito test (Maths) & 42.5 & 10.9 \\
PRIMA test (Language) & 1124.4 & 38.8 \\
PRIMA test (Maths) & 123.0 & 13.5 \\
Share of immigrant students & 0.14 & 0.17 \\
Hours of remedial teaching & 10.0 & 11.8 \\
1 if boy & 0.50 & 0.50 \\
Age of students in the 8th grade & 11.4 & 0.5 \\
1 if the teacher is male & 0.64 & 0.48 \\
Experience 8th grade teacher (years) & 20.1 & 10.2 \\
Number of students in 8th grade class & 20.1 & 7.3 \\
1 if students study with other grade students & 0.31 & 0.46 \\
Education father & & \\
1 if Primary school & 0.04 & 0.20 \\
1 if Lower secondary school & 0.44 & 0.50 \\
1 if Upper secondary school & 0.32 & 0.47 \\
1 if University & 0.21 & 0.40 \\
Education Mother & & \\
1 if Primary school & 0.04 & 0.19 \\
1 if Lower secondary school & 0.42 & 0.49 \\
1 if Upper secondary school & 0.38 & 0.49 \\
1 if University & 0.15 & 0.36 \\
Observations & \multicolumn{2}{c}{10252} \\
\hline
\end{tabular}




\section{Appendix 2 - Baseline parameter estimates}

Table 7 presents all parameter estimates for the median regression of the third column of Table 4 in more detail, to illustrate the effects of the classroom characteristics and the parental education variables. It is clear that to the extent that a higher share of immigrants leads to more educational resources, this does not have an effect on the test scores of native children, neither for language nor for math. Furthermore, the parameter estimates suggest that, compared to girls, boys perform significantly worse in language tests but significantly better in math tests. The older the child the lower the CITOscores. This may be due to the fact that older children are those who typically repeat the same grade at some point during their primary school education due to their weak academic performance. The experience of the teacher seems to be particularly important for maths. Not surprisingly, the higher the parental education the higher the CITO-scores of their children. In fact, the impact of parental education is much bigger than any of the other characteristics. For example children who have a father with a university education have a $12 \%$ higher language test score and a $16 \%$ higher math test score than children whose father has primary education. For mother with a university education the effects of having a university education are even somewhat bigger. 
Table 1: Number of immigrants in 1996-2005 PRIMA data by father's country of origin

\begin{tabular}{lccc}
\hline & $(1)$ & $(2)$ & $(3)$ \\
\hline All & $\begin{array}{c}\text { First } \\
\text { generation }\end{array}$ & $\begin{array}{c}\text { Second } \\
\text { generation }\end{array}$ \\
\hline Surinam & 434 & 52 & 381 \\
Antilles & 128 & 44 & 83 \\
Moluccas & 59 & 1 & 58 \\
Turkey & 1,580 & 167 & 1,412 \\
Morocco & 1,400 & 176 & 1,221 \\
Greece & 14 & 1 & 13 \\
Spain & 44 & 10 & 34 \\
Italy & 30 & 3 & 25 \\
Portugal & 29 & 6 & 23 \\
Yugoslavia & 170 & 94 & 75 \\
China & 96 & 11 & 84 \\
Vietnam & 56 & 10 & 46 \\
Others & 1,184 & 433 & 748 \\
Unknown & 11 & 3 & 6 \\
Total & 5,235 & 1,011 & 4,209 \\
\hline
\end{tabular}

This table presents the number of immigrants in the raw 1996-2005 PRIMA data by immigrant ethnicity, which was measured by fathers' country of origin. Although not included in this paper, the statistics calculated by mothers' country of origin look very similar to those presented in this table. The number of immigrants seem large in comparison to that of native Dutch students in the other tables. This is because the sample for the native Dutch students only include students who answered all the relevant questions and further sample selection was performed to only include schools with only one class per cohort. Such selection, however, is not performed here. 
Table 2: Average educational performance of native Dutch children and immigrant children

\begin{tabular}{lcc}
\hline & Language & Math \\
\hline a. Main groups & & \\
\hline Natives & 41.5 & 42.1 \\
Immigrants & 37.1 & 38.7 \\
Test of equality (P-values) & $0.00^{* * *}$ & $0.00^{* * *}$ \\
\hline b. Immigrant groups by generation & & \\
\hline By generation & & \\
$\quad$ First-generation (FG) & 37.2 & 38.7 \\
$\quad$ Second-generation (SG) & 36.6 & 38.7 \\
$\quad$ Test of equality & 0.15 & 0.93 \\
\hline c. Immigrant groups by parental education & & \\
\hline Less educated (LE) & 35.6 & 37.6 \\
$\quad$ Highly educated (HE) & 38.5 & 39.4 \\
Test of equality (P-values) & $0.00^{* * *}$ & $0.00^{* * *}$ \\
\hline
\end{tabular}

This table presents average Cito language and maths test scores by natives and immigrant students. Panels b and $\mathrm{c}$ further divide the immigrant groups by generation and parental education. T-tests on the equality of estimated means are conducted. 
Table 3: Estimated peer effects at the conditional mean

\begin{tabular}{|c|c|c|c|c|}
\hline & Share of immigrants & s.e. & Covariates & School fixed effects \\
\hline \multicolumn{5}{|c|}{ Language } \\
\hline (1) & $-0.21^{* * *}$ & 0.05 & & \\
\hline$(2)$ & $-0.07 * *$ & 0.03 & $\mathrm{x}$ & \\
\hline (3) & 0.06 & 0.06 & $\mathrm{x}$ & $\mathrm{x}$ \\
\hline \multicolumn{5}{|c|}{ Maths } \\
\hline (4) & $-0.13^{* * *}$ & 0.03 & & \\
\hline (5) & $-0.07 * *$ & 0.03 & $\mathrm{x}$ & \\
\hline (6) & 0.06 & 0.07 & $\mathrm{x}$ & $\mathrm{x}$ \\
\hline
\end{tabular}

Note: The parameter estimates are based on 10252 observations from 334 schools; standard errors are in parenthesis; the ${ }^{* *}(*)$ indicate significance at a $5 \%(10 \%)$ level. 
Table 4: Quantile regression test scores: Baseline estimates

\begin{tabular}{lcccccc}
\hline \multicolumn{5}{c}{ Language } & \multicolumn{5}{c}{ Maths } \\
\hline \multirow{4}{*}{10 th } & $(1)$ & $(2)$ & $(3)$ & $(4)$ & $(5)$ & $(6)$ \\
& & & & & & \\
30 th & $-0.41^{* * *}$ & -0.06 & 0.08 & $-0.26^{* * *}$ & -0.10 & 0.09 \\
& $(0.09)$ & $(0.05)$ & $(0.06)$ & $(0.07)$ & $(0.06)$ & $(0.08)$ \\
50 th & $-0.26^{* * *}$ & $-0.07^{*}$ & 0.05 & $-0.19^{* * *}$ & $-0.08^{* *}$ & 0.02 \\
& $(0.06)$ & $(0.04)$ & $(0.05)$ & $(0.04)$ & $(0.04)$ & $(0.06)$ \\
70 th & $-0.20^{* * *}$ & $-0.06^{* *}$ & 0.04 & $-0.12^{* * *}$ & $-0.08^{* * *}$ & 0.04 \\
& $(0.06)$ & $(0.02)$ & $(0.05)$ & $(0.04)$ & $(0.03)$ & $(0.06)$ \\
90th & $-0.25^{* *}$ & $-0.04^{* *}$ & 0.05 & $-0.06^{* *}$ & $-0.06^{* * *}$ & 0.06 \\
& $(0.10)$ & $(0.02)$ & $(0.06)$ & $(0.02)$ & $(0.02)$ & $(0.06)$ \\
& -0.06 & $-0.03^{*}$ & 0.06 & $-0.05^{* *}$ & $-0.03^{* *}$ & 0.08 \\
Covariates & $(0.04)$ & $(0.02)$ & $(0.06)$ & $(0.02)$ & $(0.01)$ & $(0.06)$ \\
School FE & & $\mathrm{x}$ & $\mathrm{x}$ & & $\mathrm{x}$ & $\mathrm{x}$ \\
Test of equality & $0.00^{* * *}$ & 0.71 & 0.54 & $0.00^{* * *}$ & 0.36 & 0.19 \\
\hline
\end{tabular}

Note: The parameter estimates are based on 10252 observations from 334 schools; standard errors are in parenthesis; the ${ }^{* *}(*)$ indicate significance at a $5 \%(10 \%)$ level. 
Table 5: Sensitivity analysis: Spillover effects from various immigrant groups

\begin{tabular}{|c|c|c|c|c|c|c|}
\hline & $\mathrm{FG}$ & Low edu & High edu & Repeaters & $\begin{array}{c}\text { Multiple } \\
\text { classes }\end{array}$ & $\begin{array}{c}\text { Multiple } \\
\text { classes } \\
\text { (Grade } \\
\text { share) }\end{array}$ \\
\hline a. Language & (1) & $(2)$ & $(3)$ & (4) & $(5)$ & (6) \\
\hline 10th & $\begin{array}{l}-0.15 \\
(0.16)\end{array}$ & $\begin{array}{l}-0.05 \\
(0.12)\end{array}$ & $\begin{array}{l}0.13^{*} \\
(0.07)\end{array}$ & $\begin{array}{c}0.08 \\
(0.07)\end{array}$ & $\begin{array}{l}-0.06 \\
(0.05)\end{array}$ & $\begin{array}{l}-0.01 \\
(0.06)\end{array}$ \\
\hline \multirow[t]{2}{*}{30 th } & -0.11 & -0.07 & 0.07 & 0.06 & -0.02 & 0.02 \\
\hline & $(0.11)$ & $(0.10)$ & $(0.06)$ & $(0.06)$ & $(0.04)$ & $(0.05)$ \\
\hline \multirow[t]{2}{*}{50 th } & $-0.17^{*}$ & -0.03 & 0.04 & 0.04 & -0.03 & 0.01 \\
\hline & $(0.10)$ & $(0.09)$ & $(0.06)$ & $(0.06)$ & $(0.04)$ & $(0.05)$ \\
\hline \multirow[t]{2}{*}{ 70th } & -0.17 & -0.01 & 0.05 & 0.06 & -0.02 & 0.03 \\
\hline & $(0.12)$ & $(0.10)$ & $(0.06)$ & $(0.06)$ & $(0.04)$ & $(0.05)$ \\
\hline \multirow[t]{2}{*}{90 th } & -0.06 & 0.03 & 0.06 & 0.06 & 0.00 & 0.05 \\
\hline & $(0.13)$ & $(0.09)$ & $(0.06)$ & $(0.06)$ & $(0.04)$ & $(0.05)$ \\
\hline \multirow{2}{*}{$\begin{array}{r}\text { Test of equality } \\
\text { b. Maths }\end{array}$} & 0.36 & 0.56 & 0.31 & 0.54 & 0.32 & 0.39 \\
\hline & (7) & (8) & (9) & (10) & (11) & $(12)$ \\
\hline \multirow[t]{2}{*}{10 th } & 0.10 & 0.17 & 0.07 & 0.09 & 0.00 & 0.04 \\
\hline & $(0.19)$ & $(0.13)$ & $(0.10)$ & $(0.08)$ & $(0.07)$ & $(0.07)$ \\
\hline \multirow[t]{2}{*}{30 th } & -0.07 & 0.05 & 0.00 & 0.04 & -0.02 & 0.02 \\
\hline & $(0.14)$ & $(0.10)$ & $(0.07)$ & $(0.07)$ & $(0.05)$ & $(0.06)$ \\
\hline \multirow{2}{*}{50 th } & -0.05 & 0.11 & 0.01 & 0.04 & -0.00 & 0.04 \\
\hline & $(0.11)$ & $(0.10)$ & $(0.07)$ & $(0.07)$ & $(0.05)$ & $(0.05)$ \\
\hline \multirow[t]{2}{*}{ 70th } & 0.01 & $0.18^{* *}$ & 0.03 & 0.06 & 0.03 & 0.07 \\
\hline & $(0.12)$ & $(0.09)$ & $(0.07)$ & $(0.07)$ & $(0.05)$ & $(0.05)$ \\
\hline \multirow[t]{2}{*}{90 th } & 0.09 & $0.18^{*}$ & 0.05 & 0.08 & 0.04 & 0.08 \\
\hline & $(0.13)$ & $(0.09)$ & $(0.07)$ & $(0.07)$ & $(0.05)$ & $(0.06)$ \\
\hline Test of equality & 0.22 & 0.13 & 0.52 & 0.27 & 0.11 & 0.10 \\
\hline \multirow{4}{*}{$\begin{array}{r}\text { No. of observations } \\
\text { No. of schools } \\
\text { Covariates } \\
\text { School FE }\end{array}$} & 10252 & 10252 & 10252 & 10513 & 14984 & 14984 \\
\hline & 334 & 334 & 334 & 334 & 431 & 431 \\
\hline & $\mathrm{x}$ & $\mathrm{x}$ & $\mathrm{x}$ & $\mathrm{x}$ & $\mathrm{x}$ & $\mathrm{x}$ \\
\hline & $\mathrm{x}$ & $\mathrm{x}$ & $\mathrm{x}$ & $\mathrm{x}$ & $\mathrm{x}$ & $\mathrm{x}$ \\
\hline
\end{tabular}

Note: This table shows estimated spillover effects from various immigrant groups. "FG" refers to the first-generation immigrants (i.e. a student who is foreign born and at least one parent is also foreign born). "Low edu" refers to the share of immigrant students whose parents only have primary school education. "High edu", on the other hand, includes students whose parents have lower secondary education or more. "Multiple classes" include schools with multiple 8th grade classes per cohort. Finally, "Multiple classes (Grade share)" uses the same sample as column (5), but the shares of immigrants are now calculated at the grade level and not at the class level. Standard errors are in parenthesis; the ${ }^{* *}\left({ }^{*}\right)$ indicate significance at a $5 \%(10 \%)$ level. 
Table 6: Sensitivity analysis: Estimated spillover effects in 4th, 6th, 8th grades

\begin{tabular}{lcccccc}
\hline & Language & \multicolumn{5}{c}{ Maths } \\
\hline & Fourth & Sixth & Eighth & Fourth & Sixth & Eighth \\
\hline \multirow{4}{*}{ 10th } & $(1)$ & $(2)$ & $(3)$ & $(4)$ & $(5)$ & $(6)$ \\
& & & & & & \\
30th & 0.00 & 0.01 & $0.01^{*}$ & -0.05 & -0.03 & 0.02 \\
& $(0.01)$ & $(0.00)$ & $(0.01)$ & $(0.03)$ & $(0.02)$ & $(0.02)$ \\
50 th & 0.01 & $0.01^{*}$ & $0.01^{* *}$ & -0.03 & -0.02 & 0.02 \\
& $(0.01)$ & $(0.00)$ & $(0.01)$ & $(0.03)$ & $(0.02)$ & $(0.02)$ \\
70th & 0.01 & $0.01^{*}$ & $0.01^{* *}$ & -0.02 & -0.02 & 0.02 \\
& $(0.01)$ & $(0.00)$ & $(0.01)$ & $(0.03)$ & $(0.02)$ & $(0.02)$ \\
90th & 0.01 & 0.01 & 0.01 & -0.01 & -0.02 & 0.02 \\
& $(0.01)$ & $(0.01)$ & $(0.01)$ & $(0.03)$ & $(0.02)$ & $(0.02)$ \\
& $0.01^{* *}$ & 0.00 & 0.01 & -0.01 & -0.01 & 0.02 \\
No. of observations & $(0.01)$ & $(0.01)$ & $(0.01)$ & $(0.04)$ & $(0.02)$ & $(0.02)$ \\
No. of schools & 13687 & 14126 & 9767 & 13687 & 14126 & 9767 \\
Covariates & 418 & 421 & 334 & 418 & 421 & 334 \\
School FE & $\mathrm{x}$ & $\mathrm{x}$ & $\mathrm{x}$ & $\mathrm{x}$ & $\mathrm{x}$ & $\mathrm{x}$ \\
Test of equality & $\mathrm{x}$ & $\mathrm{x}$ & $\mathrm{x}$ & $\mathrm{x}$ & $\mathrm{x}$ & $\mathrm{x}$ \\
\hline
\end{tabular}

Note: standard errors are in parenthesis; the ${ }^{* *}(*)$ indicate significance at a $5 \%(10 \%)$ level. 
Table 7: Baseline parameter estimates; median

\begin{tabular}{|c|c|c|}
\hline & Language & Maths \\
\hline Share of immigrant student in class & $\begin{array}{c}0.04 \\
(0.05)\end{array}$ & $\begin{array}{c}0.04 \\
(0.06)\end{array}$ \\
\hline Hours of remedial teaching/100 & $\begin{array}{l}-0.07 \\
(0.05)\end{array}$ & $\begin{array}{c}0.04 \\
(0.06)\end{array}$ \\
\hline 1 if boy & $\begin{array}{c}-0.06^{* * *} \\
(0.01)\end{array}$ & $\begin{array}{c}0.07^{* * *} \\
(0.01)\end{array}$ \\
\hline Age & $\begin{array}{c}-0.05^{* * *} \\
(0.01)\end{array}$ & $\begin{array}{c}-0.06^{* * *} \\
(0.01)\end{array}$ \\
\hline Wave 1998/99 & $\begin{array}{c}0.01 \\
(0.01)\end{array}$ & $\begin{array}{c}-0.03^{* *} \\
(0.01)\end{array}$ \\
\hline Wave $2000 / 01$ & $\begin{array}{c}0.00 \\
(0.01)\end{array}$ & $\begin{array}{l}-0.02 \\
(0.01)\end{array}$ \\
\hline Wave 2002/03 & $\begin{array}{c}0.59 * * * \\
(0.01)\end{array}$ & $\begin{array}{c}0.00 \\
(0.02)\end{array}$ \\
\hline Wave 2004/05 & $\begin{array}{c}0.51^{* * *} \\
(0.02)\end{array}$ & $\begin{array}{c}-0.06^{* * *} \\
(0.02)\end{array}$ \\
\hline 1 if male teacher & $\begin{array}{c}0.02 \\
(0.01)\end{array}$ & $\begin{array}{c}0.00 \\
(0.01)\end{array}$ \\
\hline Total number of students in class & $\begin{array}{l}-0.00^{*} \\
(0.00)\end{array}$ & $\begin{array}{l}-0.00 \\
(0.00)\end{array}$ \\
\hline Years of teaching experience & $\begin{array}{c}0.00 \\
(0.00)\end{array}$ & $\begin{array}{l}0.00 * * \\
(0.00)\end{array}$ \\
\hline Whether combination class or not & $\begin{array}{c}0.01 \\
(0.01)\end{array}$ & $\begin{array}{c}0.02 \\
(0.02)\end{array}$ \\
\hline Father: Lower secondary education & $\begin{array}{c}0.04 \\
(0.02)\end{array}$ & $\begin{array}{c}0.08 * * * \\
(0.02)\end{array}$ \\
\hline Father: Upper secondary education & $\begin{array}{c}0.09 * * * \\
(0.02)\end{array}$ & $\begin{array}{c}0.13^{* * *} \\
(0.02)\end{array}$ \\
\hline Father: University & $\begin{array}{c}0.12^{* * *} \\
(0.02)\end{array}$ & $\begin{array}{c}0.16^{* * *} \\
(0.02)\end{array}$ \\
\hline Mother: Lower secondary education & $\begin{array}{c}0.05^{* * *} \\
(0.02)\end{array}$ & $\begin{array}{c}0.04 \\
(0.03)\end{array}$ \\
\hline Mother: Upper secondary education & $\begin{array}{c}0.12^{* * *} \\
(0.02)\end{array}$ & $\begin{array}{c}0.12^{* * *} \\
(0.03)\end{array}$ \\
\hline Mother: University & $\begin{array}{c}0.16^{* * *} \\
(0.02)\end{array}$ & $\begin{array}{c}0.17^{* * *} \\
(0.03)\end{array}$ \\
\hline
\end{tabular}

Note: The parameter estimates are based on 10252 observations from 334 schools; the estimates presented here are the same as for the median regression in the third column of Table 4; constants are included but not reported; standard errors are in parenthesis; the ${ }^{* *}(*)$ indicate significance at a $5 \%(10 \%)$ level. 
Figure 1: Educational attainment of native Dutch children by proportion of immigrant students in the classroom

a. Language

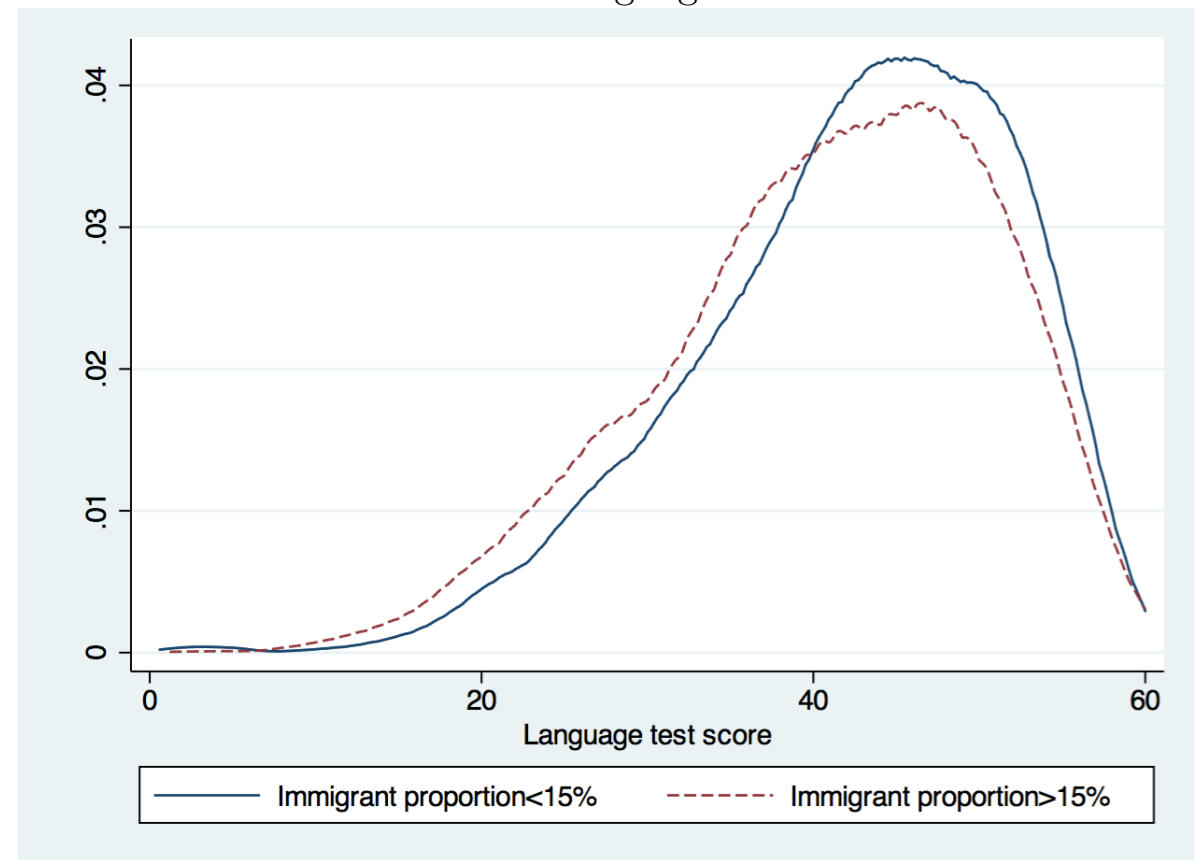

b. Math

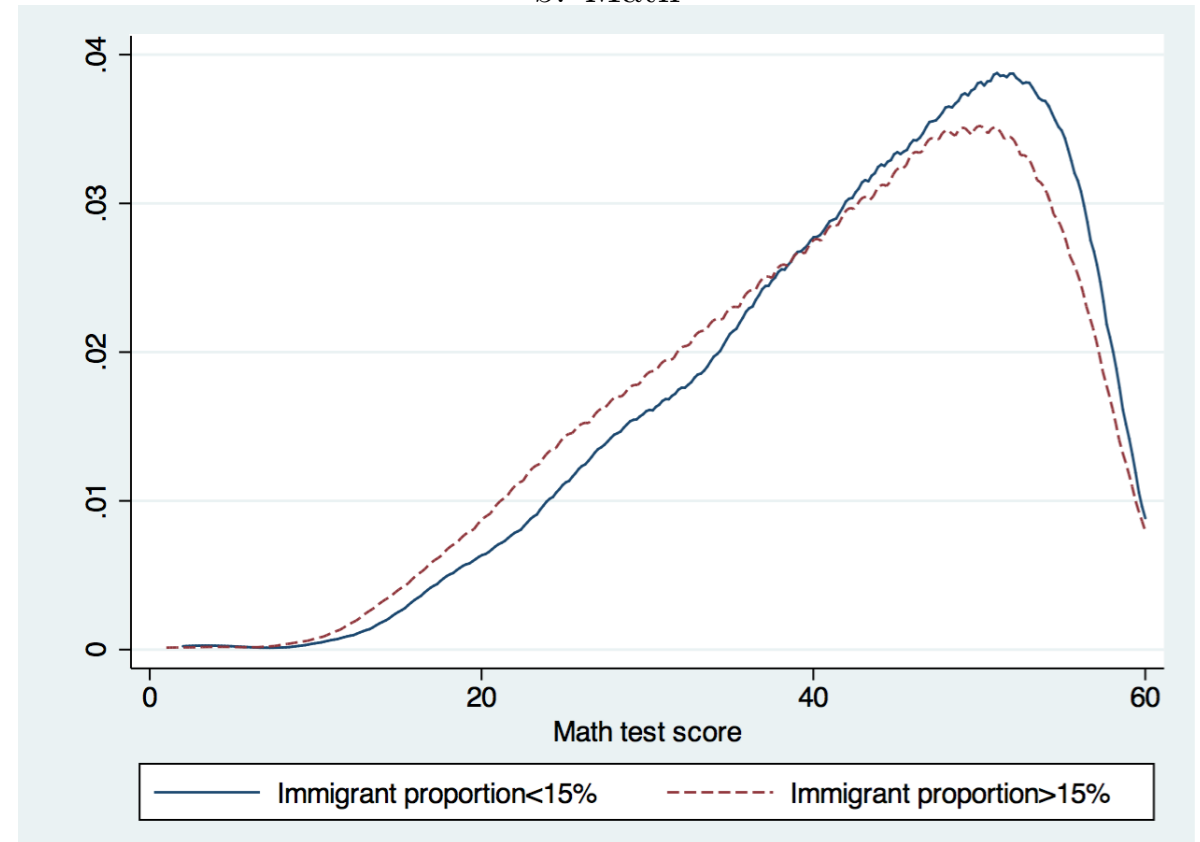

The top panel a shows the language test scores Kernel density plots whilst the bottom panel b illustrates the Kernel density plots for the maths test scores. In both figures, blue and red lines each indicates the density plot for classes with less than or more than $15 \%$ share of immigrants, respectively. 
Figure 2: Share of immigrant students and educational attainment of native Dutch children

a. Language
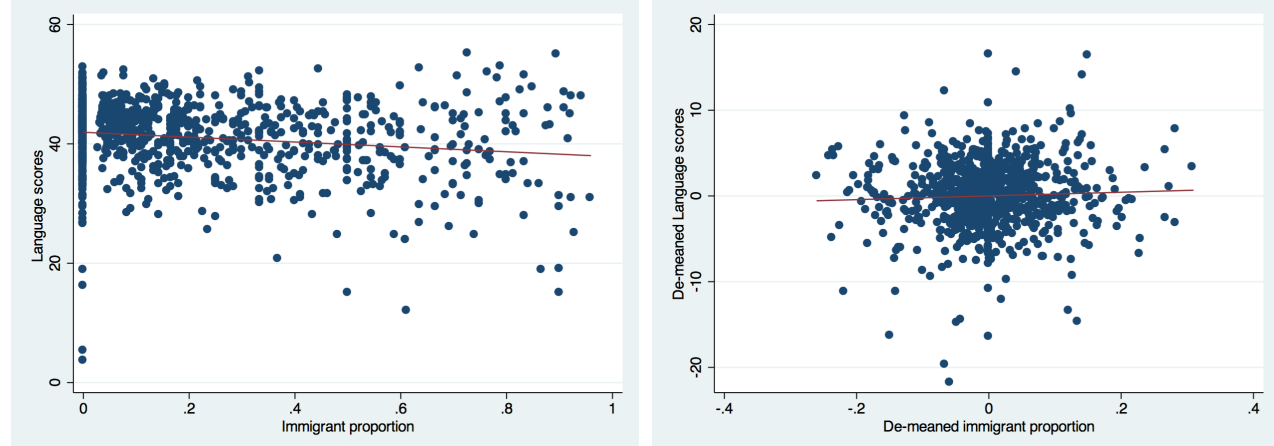

b. Math
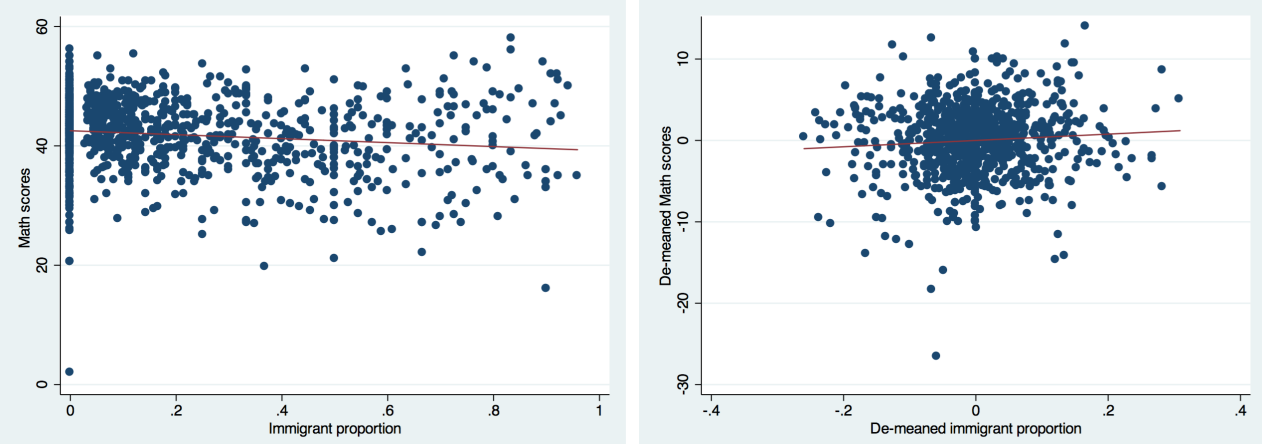

The left hand side figures include the scatter plots between the classroom average language or maths test scores against the share of immigrant students in classes. On the other hand, the right hand side figures present the scatter plots of within transformed class-level language and maths test scores against the de-meaned share of immigrant students in classes. 